Original Research

\title{
Stability Analysis of Landfill under Multi-Point Seismic Ground Motions Considering the Effect of Leachate
}

\author{
Wentao Shang, 2*, Shulin Sun ${ }^{3}$, Huanjie Liu ${ }^{4}$, Jianbo Zheng² \\ ${ }^{1}$ Research Center of Geotechnical and Structural Engineering, Shandong University, Jinan, Shandong, China \\ ${ }^{2}$ College of Architectural Engineering, Binzhou University, Binzhou, Shandong, China \\ ${ }^{3}$ School of Earth Sciences and Engineering, Hohai University, Nanjing, Jiangsu, China \\ ${ }^{4}$ China Railway No. 10 Engineering Group Co., Ltd, Jinan, Shandong, China
}

Received: 8 February 2019

Accepted: 24 April 2019

\begin{abstract}
By simulating the multipoint seismic ground motions varied with time and space, which transforms into a multi-point seismic load, and introducing calculation of water pressure, the multi-point seismic stability analysis method considering leachate is derived. A method of solving safety factor and deviation analysis is proposed and the calculation program is compiled, with which the sensitivity of the influencing factors is analyzed. The results show that the safety factor when considering the leachate, which declines linearly as the leachate level increases, is smaller than that without consideration; the safety factor shows a linear decreasing trend as the specific weight $\gamma_{\mathrm{sw}}$ increases, which is more obvious as $\gamma_{\mathrm{sw}}$ increases. The effect of $\delta_{p}$, the friction angle of the interface between the landfill and the bottom liner, on the safety factor is obviously larger than that of the cohesion $c_{p}$; whatever the leachate level is, as $a_{\max }$, the maximum acceleration of seismic ground motions increases, and the safety factor shows a declining trend. The calculation of stability analysis considering leachate level influences the safety factor of the landfill, which has important significance for the evaluation of stability and safety of the landfill in wet and rainy areas.
\end{abstract}

Keywords: landfill, leachate, multi-point seismic ground motion, stability analysis, safety factor

\section{Introduction}

In recent years, instability of landfills occurs frequently in the process of construction, operation and closure, which poses a great threat to human life, property and living environment. Therefore, ensuring the stability of sanitary landfills is the first prerequisite for their workability [1]. Landfill is different from slope. The main form of instability failure is translational failure [2]. The influencing factors are various and include changes of mechanical parameters of landfill, mechanical parameters of liner surface, leachate water level, height of landfill, and earthquake. 
The impact of an earthquake on landfill stability is incomparable in terms of scale, economic loss and difficulty in post-disaster reconstruction. Therefore, many scholars have studied the seismic stability of sanitary landfills. The dynamic characteristics and parameters of manually prepared solid waste samples were studied by using a medium-sized cyclic triaxial tester [3, 4]. Annapareddy [5], Feng [6, 7], Ruan [8], and Zhu [9] used the limit equilibrium method to analyze landfill seismic stability and permanent displacement. However, at present the research on the ground motion of landfill mainly focuses on the stability and dynamic response analysis under uniform ground motion, that is, the same ground motion input is used for the whole landfill, without considering the time-space process of actual ground motion. Many engineering cases show that whether the time-space variability of ground motion is considered in seismic analysis, has great influence on the stability of engineering [10, 11].

In addition, Peng [12] back-analyzed Shenzhen landfill failure induced by high water levels; Khoshand [13] evaluated the stability of a reinforced tapered landfill cover system under seismic and seepage loading conditions; Qian [14] calculated the influence of four different distribution forms of leachate on the stability of landfills; and Feng [15] investigated the influence of leachate injection on landfill slope stability. Many studies on landfill stability show that leachate is also an important factor threatening stability.

On the basis of Qian's [14] landfill translational stability analysis method, considering the influence of multi-point seismic load and leachate, this paper establishes a multi-point seismic stability analysis method for landfill considering the influence of leachate, and solves the safety factor. At the same time, the mechanical parameters of landfill body, the mechanical parameters of lining surface, the level of leachate, the height of landfill and earthquake affect on landfill stability are studied.

\section{Material and Methods}

\section{Artificial Synthesis of Multi-Point Ground Motion}

Acquiring actual multi-point earthquake motion is a precondition for the landfill stability analysis under a multi-point earthquake. However, there are few recorded multi-point ground motions at home and abroad, with most studies adopting the method of synthesizing spatially correlated and random multi-point ground motions. Researchers have proposed some methods to synthesize multi-point ground motions. Among them, $\mathrm{Qu}[16,17]$ proposed a multi-point ground motion simulation method based on the records of Taiwan Smart-1 seismic array. The multi-point ground motions were simulated based on this method.

\section{Power Spectrum Matrix Generation}

The precondition of synthesizing spatially correlated multi-point stationary ground motions is the spectral matrix of generation success rate.

$$
S\left(i \omega_{i}\right)=\left[\begin{array}{cccc}
S_{1}\left(i \omega_{i}\right) & S_{12}\left(i \omega_{i}\right) & \ldots & S_{1 n}\left(i \omega_{i}\right) \\
S_{21}\left(i \omega_{i}\right) & S_{2}\left(i \omega_{i}\right) & \ldots & S_{2 n}\left(i \omega_{i}\right) \\
\ldots & \ldots & \ddots & \ldots \\
S_{n 1}\left(i \omega_{i}\right) & S_{n 2}\left(i \omega_{i}\right) & \ldots & S_{n}\left(i \omega_{i}\right)
\end{array}\right]
$$

In the formula, the diagonal element of the power spectrum matrix is self-power spectrum, the other elements are cross-power spectrum.

The Hu Yuxian model was used as a stationary autopower spectrum model, i.e., the modified Kainai model:

$$
S(\omega)=\frac{\omega^{2}}{\omega^{2}+\omega_{g}^{2}} \frac{1+4 \xi_{g}^{2} \frac{\omega^{2}}{\omega_{g}^{2}}}{\left(1-\frac{\omega^{2}}{\omega_{g}^{2}}\right)^{2}+4 \xi_{g}^{2} \frac{\omega^{2}}{\omega_{g}^{2}}} S_{0}
$$

In formula:

$\omega_{\mathrm{g}}$ is the fundamental frequency of the site

$\xi_{\mathrm{g}}$ is site damping

$S_{0}$ is the power spectrum intensity of white noise

$\omega$ is the low frequency cut-off frequency

The cross power spectrum of any two points $i$ and $j$ in space is:

$$
S_{i j}(i \omega)=\sqrt{S_{i}(i \omega) S_{j}(i \omega)}\left|\rho_{i j}\left(d_{i j}, \omega\right)\right| e^{-i \omega \frac{d_{i j}}{v_{a}(\omega)}}
$$

In the formula, $d_{i j}$ is the projection of the vector connecting two points in the incident direction of seismic wave, which can be divided into positive and negative.

$v_{a}(\omega)$ is the apparent wave velocity and the function of frequency, but for simplification, it is usually taken as a fixed value.

$\left|\rho_{i j}\left(d_{i j}, \omega\right)\right|$ is a hysteresis correlation function. In this paper, Feng and $\mathrm{Hu}$ models are used.

$$
\rho_{i j}\left(d_{i j}, \omega\right)=e^{-\left(\rho_{l} \omega+\rho_{2}\right)\left|d_{i j}\right|}
$$

The hysteresis correlation function between two ground motions in the same direction is expressed. From the point of engineering application, it is approximated that the correlation function is completely acceptable independent of azimuth. At the same time, the correlation between horizontal and vertical components is always less than that between two horizontal components. The measured data show that the correlation function of horizontal and vertical components is about 0.5 in the low-frequency part and slightly less than 0.3 in the highfrequency part. As for the value of 2-point heterotrophic 
correlation function, it can be assumed that the value of 2-point homotopic correlation function is multiplied by the value of the correlation function of the horizontal and vertical components of the same point.

The diagonal elements in the power spectrum matrix can be obtained from the self-power spectrum model, and the other elements in the power spectrum matrix can be obtained from the cross-power spectrum model, thus the power spectrum matrix can be obtained.

\section{Multipoint and Multidirectional Ground Motion Synthesis}

When the time history of ground motion at $\mathrm{n}$ points is generated, the spatial correlation of ground motion at each point is taken into account with that at other $\mathrm{n}-1$ points. The synthetic formula of this method is as follows:

$$
\left\{\begin{array}{c}
u_{1}(t)=\sum_{m=1}^{n} \sum_{k=0}^{n-1} a_{1 m}\left(\omega_{k}\right) \cos \left[\omega_{k} t+\theta_{1 m}\left(\omega_{k}\right)+\varphi_{m k}\right] \\
u_{2}(t)=\sum_{m=1}^{n} \sum_{k=0}^{n-1} a_{2 m}\left(\omega_{k}\right) \cos \left[\omega_{k} t+\theta_{2 m}\left(\omega_{k}\right)+\varphi_{m k}\right] \\
\mathrm{L} \mathrm{L} \\
u_{n}(t)=\sum_{m=1}^{n} \sum_{k=0}^{n-1} a_{n m}\left(\omega_{k}\right) \cos \left[\omega_{k} t+\theta_{n m}\left(\omega_{k}\right)+\varphi_{m k}\right]
\end{array}\right.
$$

In the formula, $a_{n m}\left(\omega_{k}\right)$ and the $\theta_{n m}\left(\omega_{k}\right)$ are the amplitude and phase angles of the $k$-th frequency component considering the correlation between the $n$-th point and the $m$-th point at $t$-time, respectively. They can be decomposed according to formula (1). They are deterministic quantities, and their values should satisfy the correlation and phase characteristics of the $n$-th point and the $m$-th point.

$\omega_{i}$ is frequency.

$\varphi_{m k}$ is a random phase angle, which is uniformly distributed in the $(0,2 \pi)$ interval.

The ground motions at each point synthesized by formula (5) are stable, but the actual seismic records show that the ground motions are non-stationary. In order to obtain the non-stationary ground motions, the multi-point and multi-direction non-stationary seismic accelerations can be obtained by multiplying the ground motions synthesized by formula (5) by the intensity envelope function $f(t)$, which can be used to analyze the seismic stability of landfill sites. Its expression is:

$$
f(t)=\left\{\begin{array}{cc}
\left(t / t_{1}\right)^{2} & t<t_{1} \\
1 & t_{1}<t<t_{2} \\
e^{-c\left(t-t_{2}\right)} & t>t_{2}
\end{array}\right.
$$

In the formula:

$t_{1}$ is the starting time of the stationary period of ground motion

$t_{2}$ is the end time of stationary period of ground motion $c$ is the attenuation coefficient of ground motion

\section{Calculating Multi-Point Seismic Load}

Previous analysis methods for landfill stability only applied a horizontal seismic inertia force $Q_{i}$ at the center of the landfill body toward the outside of the slope (which is negative to the direction of slope stability). The magnitude of $Q_{i}$ is the seismic coefficient multiplied by the weight of the soil strip, so that the magnitude and direction of the ground motion (here referred to as seismic acceleration) are not changed with space and time. Variable constants are taken into account and the seismic acceleration applied to the whole landfill body is the same, but the magnitude and direction of the actual ground motion are changing with time and are also different in space. In order to overcome the shortcomings of the previous stability analysis methods for sanitary landfills in seismic load treatment, this study applied the upper section of artificial synthesis to landfills. Multi-point ground motion acceleration is used to analyze the stability of slope under multi-point ground motion.

Fig. 1 shows that the landfill site is divided into $n$ blocks. Assuming that the ground motion is incident by point $\mathrm{A}$ at the bottom of the slip surface and considering the multi-point and multi-direction characteristics of the ground motion, the magnitude and direction of the ground motion transmitted to each landfill block are different. As shown by $i$ in the figure, the horizontal and vertical ground motion accelerations $a_{H i}, a_{V i}$ and $j$ are different $i$ in size and direction. In this paper, it is stipulated that the horizontal seismic acceleration is positive or negative in the direction of sliding, while the vertical seismic acceleration is positive downward and negative upward.

For the first section of the landfill under multi-point and multi-direction seismic action shown in Fig. 1, the forces acting on the first section are shown in Fig. 2, where $Q_{H i}$ and $Q_{V i}$ are the horizontal and vertical seismic loads on the landfill section, respectively:

$$
\begin{gathered}
Q_{H i}=k_{H i}(t) W_{i} \\
Q_{V i}=k_{V i}(t) W_{i}
\end{gathered}
$$

In the formula, $k_{H i}(t) W_{i}$ and $k_{V i}(t) W_{i}$ are defined as horizontal and vertical seismic dynamic coefficients respectively.

$$
\begin{aligned}
& k_{H i}(t)=\zeta \alpha_{i} a_{H i}(t) / g \\
& k_{V i}(t)=\zeta \alpha_{i} a_{V i}(t) / g
\end{aligned}
$$

$a_{H i}(t)$ is the value of the horizontal acceleration of the synthetic ground motion at T-time at the position of the first block, and $a_{V i}(t)$ is the value of the vertical acceleration of the synthetic ground motion at T-time at the position of the second block. It can be obtained by the method of multi-point and multi-direction ground 


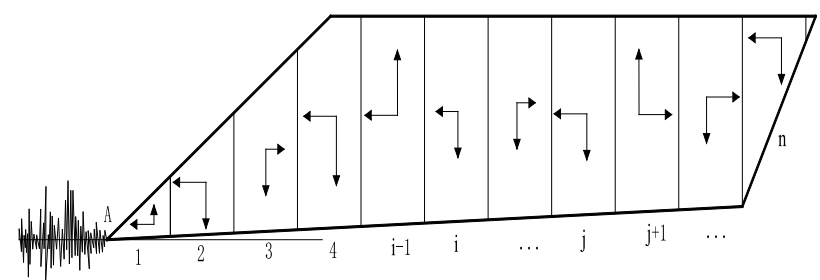

Fig. 1. Schematic map of multi-point ground motion distribution.

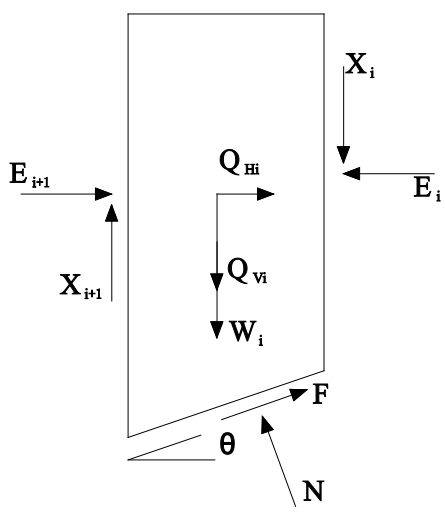

Fig. 2. Landfill block multi-point ground motion distribution diagram.

motion synthesis introduced in the preceding section. $\zeta$ is the reduction coefficient, the value is $0.25 ; \alpha_{i}$ is the dynamic distribution coefficient, according to Deng [18] shaking table test, the value is 2.0.

\section{Basic Hypothesis of Landfill Stability Calculation \\ Model Considering the Influence of Leachate}

The action force between active and passive wedge is assumed to be angled with the normal direction between active and passive wedges. The action point of the force is at $\mathrm{H} / 3$ at the bottom of the interface.

The interwedge force is assumed to be inclined at an unknown angle $\omega$ to the normal drawn to the interface between active and passive wedges (Fig. 3). The line of action of the interwedge force is

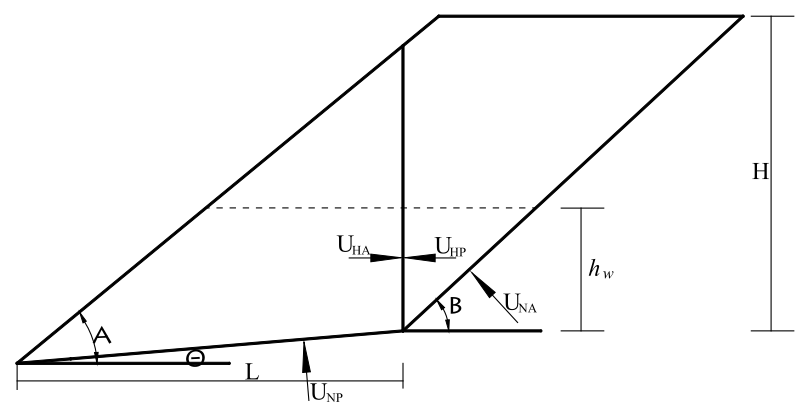

Fig. 4. Leachate distribution.

assumed to act at a distance of $\mathrm{H} / 3$ above the base of the interface. The interwedge force direction can be considered to be "floating," although it is unique for a given set of circumstances. In order to satisfy the shear failure criterion of solid waste at the interface between active and passive wedges, the average shear stress at this interface should be less than the average shear strength of the entire solid waste mass, that is, the safety factor $F S_{V}$ between active and passive blocks should not be less than 1 , nor less than the safety factor of the entire solid waste mass. The safety factor of landfill is the same at all points on the failure surface [19].

The calculation method of leachate head pressure established by Qian [14] is used. The horizontal distribution of leachate is assumed (as shown in Fig. 4). The pressure acting on backing and bottom liner can be calculated by the following formula:

$$
\begin{gathered}
U_{H A}=U_{H P}=0.5 \cdot \rho_{w} \cdot g \cdot h_{w}{ }^{2} \\
U_{N A}=0.5 \cdot \rho_{w} \cdot g \cdot h_{w}{ }^{2} / \sin \beta \\
U_{N P}=\rho_{w} \cdot g \cdot\left(h_{w}+0.5 \cdot L \cdot \tan \theta\right)
\end{gathered}
$$

\section{Limit Equilibrium Analysis of Active and Passive Blocks}

The passive wedge satisfies the equilibrium condition of force in the y direction.

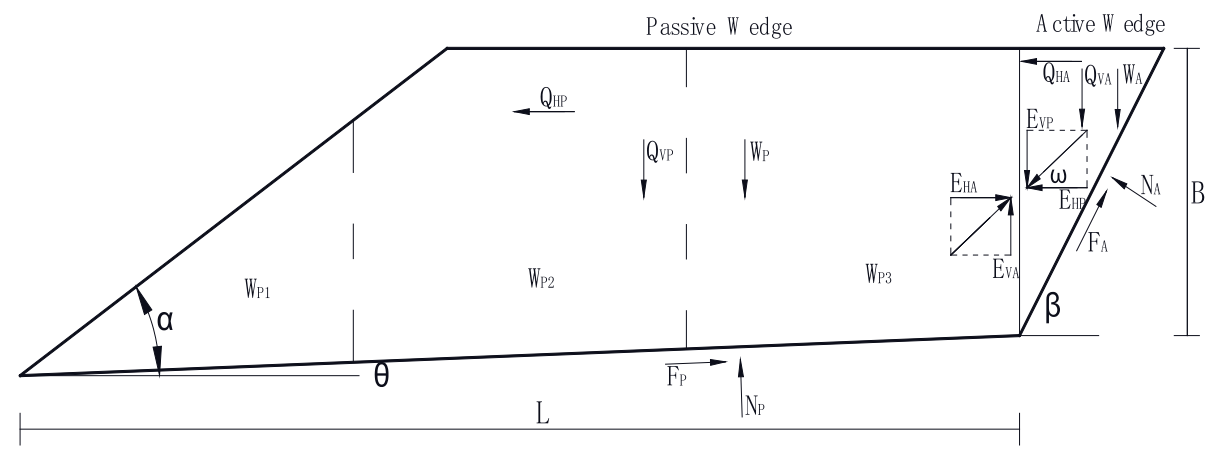

1. $5 \mathrm{H}: 1 \mathrm{~V} \alpha=33.7^{\circ} \quad \beta=60^{\circ} \quad \theta=2^{\circ}$

Fig. 3. Forces in the landfill. 
$W_{P}+E_{V P}+Q_{V P}=N_{P} \cdot \cos \theta+U_{N P} \cdot \cos \theta+F_{P} \cdot \sin \theta$

$$
\begin{gathered}
F_{P}=C_{P} / F S_{P}+N_{P} \cdot \tan \delta_{p} / F S_{P} \\
E_{V P}=C_{S W} / F S_{V}+E_{H P} \cdot \tan \phi_{S W} / F S_{V}
\end{gathered}
$$

It is assumed here that:

$$
\begin{gathered}
m_{s w}=\tan \phi_{S W} / F S_{V} \\
n_{s w}=C_{S W} / F S_{V}
\end{gathered}
$$

By substituting (17), (18) for (16), the following results can be obtained:

$$
E_{V P}=n_{s w}+E_{H P} \cdot m_{s w}
$$

Substitute (15), (19) into (14):

$$
\begin{gathered}
W_{P}+Q_{V P}+n_{s w}+E_{H P} \cdot m_{s w}=N_{P} \cdot(\cos \theta+\sin \theta \\
\left.\quad \cdot \tan \delta_{p} / F S_{P}\right)+C_{P} \cdot \sin \theta / F S_{P}+U_{N P} \cdot \cos \theta
\end{gathered}
$$

The passive wedge satisfies the equilibrium condition of the force in the $\mathrm{X}$ direction.

$$
F_{P} \cdot \cos \theta=E_{H P}+Q_{H P}+U_{H P}+N_{P} \cdot \sin \theta+U_{N P} \cdot \sin \theta
$$

Substitute (15) into (21) to obtain:

$$
\begin{aligned}
& N_{P} \cdot\left(\cos \theta \cdot \tan \delta_{P} / F S_{P}-\sin \theta\right)=E_{H P}+Q_{H P} \\
& \quad+U_{H P}+U_{N P} \cdot \sin \theta-C_{P} \cdot \cos \theta / F S_{P}
\end{aligned}
$$

Substitute (22) into (20) to obtain:

$$
\begin{gathered}
E_{H P}=\left[\left(Q_{H P}+U_{H P}\right) \cdot\left(\cos \theta+\sin \theta \cdot \tan \delta_{P} / F S_{P}\right)-\left(W_{P}+Q_{V P}+n_{s w}\right)\right. \\
\left.\cdot\left(\cos \theta \cdot \tan \delta_{P} / F S_{P}-\sin \theta\right)+U_{N P} \cdot \tan \delta_{P} / F S_{P}-C_{P} / F S_{P}\right] / \\
\left(m_{s w} \cdot \cos \theta \cdot \tan \delta_{P} / F S_{P}-\sin \theta \cdot m_{s w}-\cos \theta-\sin \theta \cdot \tan \delta_{P} / F S_{P}\right)
\end{gathered}
$$

The active wedge satisfies the equilibrium condition of the force in the y direction.

$$
\begin{gathered}
W_{A}+Q_{V A}=F_{A} \cdot \sin \beta+N_{\mathrm{A}} \cdot \cos \beta+U_{N A} \cdot \cos \beta+E_{V A} \\
F_{A}=C_{A} / F S_{A}+N_{A} \cdot \tan \delta_{a} / F S_{A} \\
E_{V A}=C_{S W} / F S_{V}+E_{H A} \cdot \tan \phi_{S W} / F S_{V}
\end{gathered}
$$

By substituting (17), (18) for (26), the following results can be obtained:

$$
E_{V A}=n_{s w}+E_{H A} \cdot m_{s w}
$$

By substituting (25) and (26) into (24), the following results can be obtained:

$$
\begin{gathered}
N_{A} \cdot\left(\cos \beta+\sin \beta \cdot \tan \delta_{a} / F S_{A}\right)=W_{A}+Q_{V A}-C_{A} \\
\cdot \sin \beta / F S_{A}-U_{N A} \cdot \cos \beta-n_{s w}-E_{H A} \cdot m_{s w}
\end{gathered}
$$

The active wedge satisfies the equilibrium condition of the force in the x-direction, and can be obtained as follows:

$$
F_{A} \cdot \cos \beta+E_{H A}+U_{H A}=N_{A} \cdot \sin \beta+U_{N A} \cdot \sin \beta+Q_{H A}
$$

Substitute (25) into (29) to obtain:

$$
\begin{gathered}
N_{A} \cdot\left(\cos \beta \cdot \tan \delta_{a} / F S_{A}-\sin \beta\right)=U_{N A} \cdot \sin \beta \\
+Q_{H A}-C_{A} \cdot \cos \beta / F S_{A}-E_{H A}-U_{H A}
\end{gathered}
$$

Substitute (30) into (28) to obtain:

$$
\begin{gathered}
E_{H A}=\left[\left(W_{A}+Q_{V A}-n_{s w}\right) \cdot\left(\cos \beta \cdot \tan \delta_{a} / F S_{A}-\sin \beta\right)+C_{A} / F S_{A}-U_{N A}\right. \\
\left.\cdot \tan \delta_{a} / F S_{A}-\left(Q_{H A}-U_{H A}\right) \cdot\left(\cos \beta+\sin \beta \cdot \tan \delta_{a} / F S_{A}\right)\right] \\
/\left(m_{s w} \cdot \cos \beta \cdot \tan \delta_{a} / F S_{A}-m_{s w} \cdot \sin \beta-\cos \beta-\sin \beta \cdot \tan \delta_{a} / F S_{A}\right)
\end{gathered}
$$

According to the hypothesis and analysis in the previous chapter, the maximum safety factor $F S_{\text {max }}$ and the minimum safety factor $F S_{\text {min }}$ of landfill can be calculated by the following formula.

$F S_{\max }$ can be calculated by the following formula:

$$
\begin{gathered}
{\left[\left(Q_{H P}+U_{H P}\right) \cdot\left(\cos \theta+\sin \theta \cdot \tan \delta_{P} / F S\right)-\left(W_{P}+Q_{V P}+C_{S W} / F S\right)\right.} \\
\left.\cdot\left(\cos \theta \cdot \tan \delta_{P} / F S-\sin \theta\right)+U_{N P} \cdot \tan \delta_{P} / F S-C_{P} / F S\right] \\
/\left(\cos \theta \cdot \tan \phi_{S W} \cdot \tan \delta_{P} / F S^{2}-\cos \theta-\sin \theta \cdot \tan \delta_{P} / F S\right. \\
\left.-\tan \phi_{S W} \cdot \sin \theta / F S\right)=\left[( W _ { A } + Q _ { V A } - C _ { S W } / F S ) \cdot \left(\cos \beta \cdot \tan \delta_{a}\right.\right. \\
/ F S-\sin \beta)+C_{A} / F S-U_{N A} \cdot \tan \delta_{a} / F S-\left(Q_{H A}-U_{H A}\right) \\
\left.\cdot\left(\cos \beta+\sin \beta \cdot \tan \delta_{a} / F S\right)\right] /\left(\cos \beta \cdot \tan \phi_{S W} \cdot \tan \delta_{a} / F S^{2}-\cos \beta\right. \\
\left.-\sin \beta \cdot \tan \delta_{a} / F S-\tan \phi_{S W} \cdot \sin \beta / F S\right)
\end{gathered}
$$

$F S_{\text {min }}$ can be calculated by the following formula:

$$
\begin{gathered}
{\left[\left(W_{P}+Q_{V P}\right) \cdot\left(\cos \theta \cdot \tan \delta_{P} / F S-\sin \theta\right)-\left(Q_{H P}+U_{H P}\right)\right.} \\
\left.\cdot\left(\cos \theta+\sin \theta \cdot \tan \delta_{P} / F S\right)-U_{N P} \cdot \tan \delta_{P} / F S+C_{P} / F S\right] \\
/\left(\cos \theta+\sin \theta \cdot \tan \delta_{P} / F S\right)=\left[\left(Q_{H A}-U_{H A}\right) \cdot(\cos \beta+\sin \beta\right. \\
\left.\cdot \tan \delta_{a} / F S\right)-\left(W_{A}+Q_{V A}\right) \cdot\left(\cos \beta \cdot \tan \delta_{a} / F S-\sin \beta\right) \\
\left.+U_{N A} \cdot \tan \delta_{a} / F S-C_{A} / F S\right] /\left(\cos \beta+\sin \beta \cdot \tan \delta_{a} / F S\right)
\end{gathered}
$$

Because the presence of leachate affects the landfill weight, the physical parameters of sanitary landfill are calculated as follows:

When $(H+L \cdot \tan \theta) / \tan \alpha \leq L$,

$$
C_{S W}=c_{s w} \cdot H
$$




$$
\begin{gathered}
C_{A}=c_{a} \cdot H / \sin \beta \\
C_{P}=c_{p} \cdot L / \cos \theta \\
W_{A}=0.5 \cdot \rho_{s w} \cdot \mathrm{g} \cdot H^{2} / \tan \beta+0.5 \\
\cdot\left(\rho_{s w(s a t)}-\rho_{s w}\right) \cdot \mathrm{g} \cdot h_{w}{ }^{2} / \tan \beta \\
W_{P}=0.5 \cdot \rho_{s w} \cdot \mathrm{g} \cdot[2 L-(H+L \cdot \tan \theta) / \\
\left.\tan \alpha-\left(h_{w}+L \cdot \tan \theta\right) / \tan \alpha\right] \cdot\left(H-h_{w}\right)+0.5 \\
\rho_{s w(s a t)} \cdot \mathrm{g} \cdot\left(L-\left(h_{w}+L \cdot \tan \theta\right) / \tan \alpha+L\right) \cdot\left(h_{w}\right. \\
+L \cdot \tan \theta)-0.5 \cdot \rho_{s w(s a t)} \cdot \mathrm{g} \cdot L \cdot L \cdot \tan \theta
\end{gathered}
$$

$(H+L \cdot \tan \theta) / \tan \alpha>L$ 时,

$$
\begin{gathered}
C_{S W}=c_{s w} \cdot L \cdot(\tan \alpha-\tan \theta) \\
C_{A}=c_{a} \cdot H / \sin \beta \\
C_{P}=c_{p} \cdot L / \cos \theta \\
W_{A}=0.5 \cdot \rho_{s w} \cdot \mathrm{g} \cdot H^{2} / \tan \beta+0.5 \cdot\left(\rho_{s w(s a t)}\right. \\
\left.-\rho_{s w}\right) \cdot \mathrm{g} \cdot h_{w}^{2} / \tan \beta-0.5 \cdot \rho_{s w} \\
\cdot \mathrm{g} \cdot(H-L \cdot \tan \alpha+L \cdot \tan \theta)^{2} / \tan \alpha \\
W_{P}=0.5 \cdot \rho_{s w} \cdot \mathrm{g} \cdot L^{2} \cdot(\tan \alpha-\tan \theta)-0.5 \cdot \\
\rho_{s w(s a t)} \cdot \mathrm{g} \cdot L^{2} \cdot \tan \theta-0.5 \cdot\left(\rho_{s w(s a t)}-\rho_{s w}\right) \\
\cdot \mathrm{g} \cdot\left(L \cdot \tan \alpha-L \cdot \tan \theta-h_{w}\right)^{2} / \tan \alpha
\end{gathered}
$$

\section{Results and Discussion}

\section{Value of Calculation Parameters}

The selection of calculation parameters is shown in Table 1.

\section{Impact Analysis of Multi-Point Seismic Load}

In order to study the influence of apparent wave velocity on the stability of landfill under multipoint seismic load, at a seismic acceleration of $0.2 \mathrm{~g}$ $\left(a_{\max }=0.2 \mathrm{~g}\right)$ the safety factors are calculated with the apparent velocity being $250 \mathrm{~m} / \mathrm{s}, 500 \mathrm{~m} / \mathrm{s}, 1000 \mathrm{~m} / \mathrm{s}$ and $2000 \mathrm{~m} / \mathrm{s}$ respectively, and the calculated values are compared with those arrived at with the previous algorithm. Fig. 5 shows that:

(1) For the same sliding surface, the safety factors of the landfill under multi-point ground motion are always greater than those under single-point ground motion in

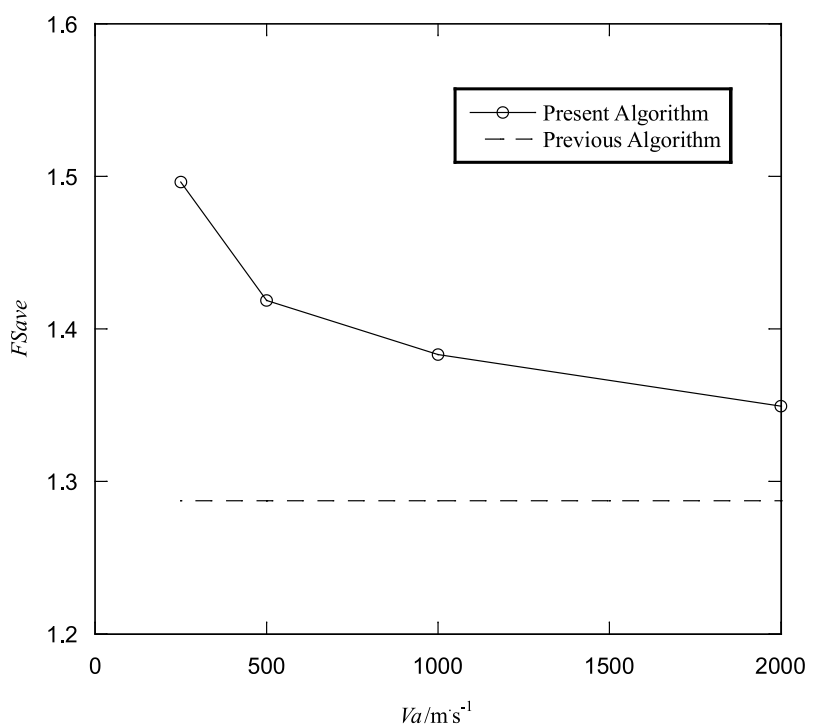

Fig. 5. Relationship between safety factor and apparent wave velocity.

the previous algorithm. They decrease as the apparent velocity $\left(v_{a}\right)$ increases gradually from $250 \mathrm{~m} / \mathrm{s}, 500 \mathrm{~m} / \mathrm{s}$, $1000 \mathrm{~m} / \mathrm{s}$ to $2000 \mathrm{~m} / \mathrm{s}$ and the decrease slows down with the increase of apparent wave velocity.

(2) At a low apparent wave velocity $\left(v_{a}\right)$, there is a huge difference between the safety factors under multipoint ground motion and the safety factors under singlepoint ground motion in the previous algorithm, and the difference becomes smaller with the increase of apparent wave velocity. Due to the effect of the traveling wave, the lower the apparent wave velocity, the more obvious the hysteresis phenomenon is compared with that under the uniform motivation of the previous algorithm. With the rise of apparent wave velocity, the hysteresis phenomenon becomes significantly less obvious, indicating that the influence of traveling wave effect under multi-point ground motion on the stability of landfill decreases with the increase of apparent velocity $\left(v_{a}\right)$.

(3) In order to study the influence of peak acceleration of multi-point ground motion on landfill stability, the safety factor of multi-point ground motion peak acceleration $a_{\max }$ at $0.05 \mathrm{~g}, 0.1 \mathrm{~g}, 0.2 \mathrm{~g}$ and $0.4 \mathrm{~g}$, respectively, and at $h_{w}$ of $0,5,10,15$ and $20 \mathrm{~m}$ were calculated. Fig. 6 shows the variation of the safety factor with the peak acceleration $a_{\max }$ of multi-point ground motion. It can be seen that the safety factor decreases with the increase of the peak acceleration $a_{\max }$ of ground motion, regardless of the water level of leachate.

Table 1. Calculation parameters in the example.

\begin{tabular}{|c|c|c|c|c|c|c|c|c|c|c|c|c|c|c|}
\hline$c_{s w}$ & $\phi_{S W}$ & $\alpha$ & $\beta$ & $\theta$ & $L$ & $H$ & $c_{a}$ & $c_{p}$ & $\delta_{a}$ & $\delta_{p}$ & $\rho_{s w}$ & $g$ & $\alpha_{i}$ & $\zeta$ \\
\hline 3.0 & $30^{\circ}$ & $33.7^{\circ}$ & $60^{\circ}$ & $2^{\circ}$ & 200 & 40 & 3.0 & 3.0 & $15^{\circ}$ & $15^{\circ}$ & $1.04 \times 10^{3}$ & 9.8 & 2.5 & 0.25 \\
\hline
\end{tabular}

Note: The units of $c_{s w}, c_{a}$ and $c_{p}$ are $\mathrm{KN} / \mathrm{m}^{2}$ and the units of $\rho_{s w}$ are $\mathrm{kg} / \mathrm{m}^{3}$ 


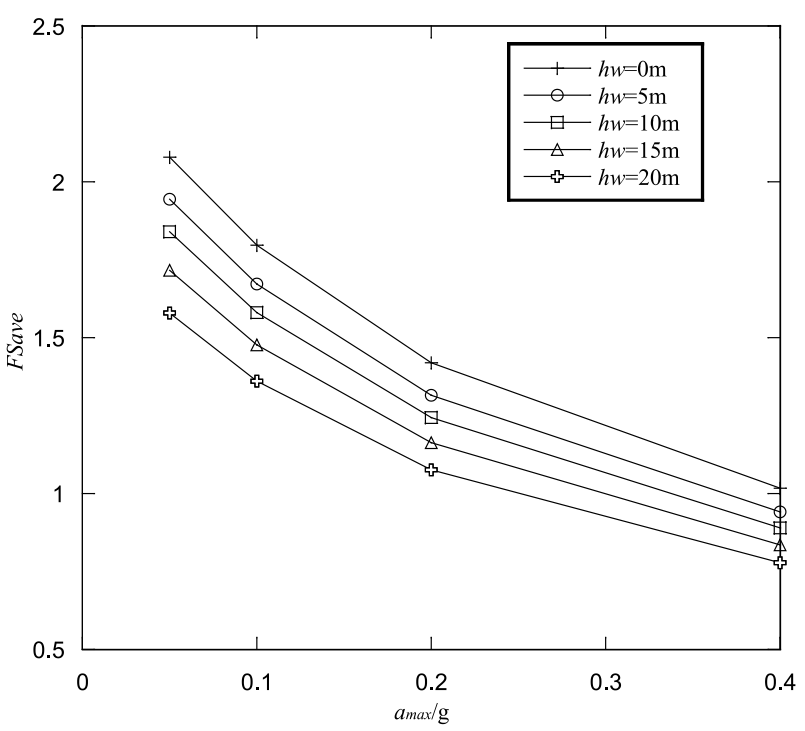

Fig. 6. Relationship between safety factor $F S$ and $a_{\max }$ considering leachates.

\section{Impact Analysis of Landfill Strength Parameters}

In order to study the influence of landfill strength parameters on the stability of a landfill under multipoint seismic loading at different leachate heights, the safety factors of cohesion $c_{s w}$ and internal friction angle $\phi_{s w}$ at $h_{w}$ of $0,5,10,15$ and $20 \mathrm{~m}$ were calculated. Fig. 7 shows the variation of the safety factor of the whole slip surface with the cohesion $c_{s w}$ (the range of $c_{s w}$ values is $5 \mathrm{kPa}, 10 \mathrm{kPa}, 15 \mathrm{kPa}, 20 \mathrm{kPa}, 25 \mathrm{kPa}, 30 \mathrm{kPa}$ ); Fig. 8 shows the variation of the safety factor of the whole slip surface with the friction angle of the landfill body (the range of the value of $\phi_{s w}$ is $20,30,40,50^{\circ}$ ). It can be seen that:

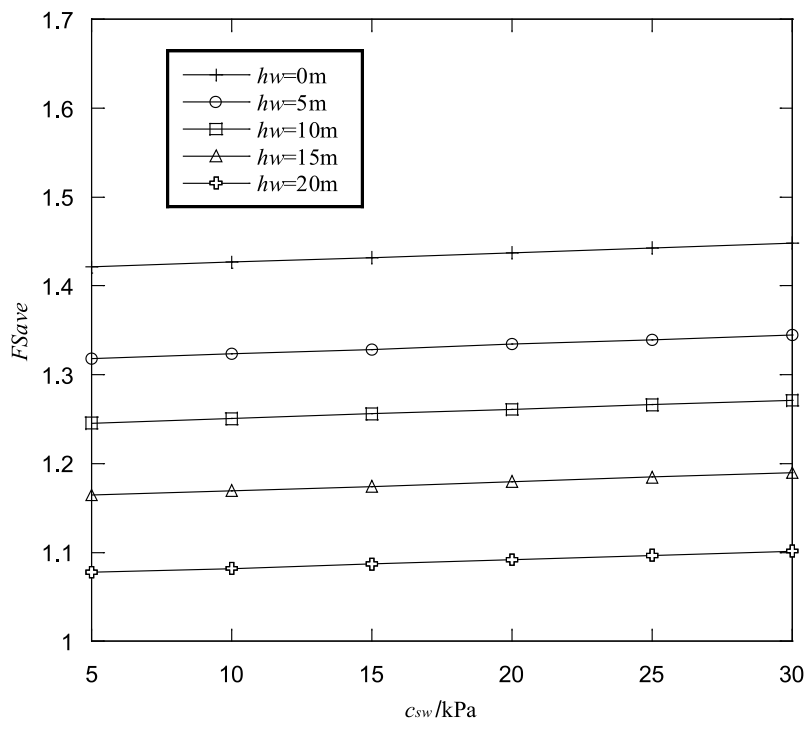

Fig. 7. Relationship between safety factor $F S$ and $c_{s w}$ considering leachates.

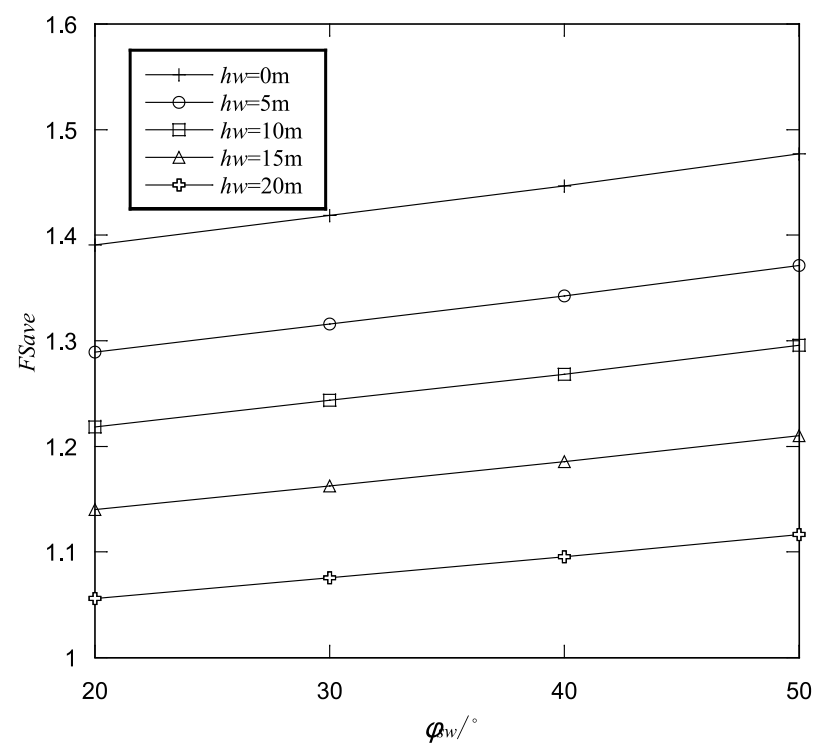

Fig. 8. Relationship between safety factor $F S$ and $\phi_{s w}$ considering leachates.

(1) In the analysis of slip stability, cohesion and internal friction angle have little influence on its stability. When $h_{w}=0$, the difference between $c=30 \mathrm{kPa}$ and $c_{s w}=5 \mathrm{kPa}$ is only 0.0278 ; when $h_{w}=0$, the difference between $\phi_{s w}=50^{\circ}$ and $\phi_{s w}=20^{\circ}$ is only 0.0944 .

(2) The safety factor considering leachate is smaller than that not considered; the safety factor decreases approximately with the increase of equidistant distance of $h_{w}$, regardless of the influence of cohesion or internal friction angle on the safety factor.

\section{Impact Analysis of Landfill Weight Parameters}

In order to study the influence of landfill weight parameters on the overall stability of landfill under multi-point seismic loading at different leachate heights, the safety factors of landfill weight $\gamma_{s w}$ at $0,5,10,15$ and $20 \mathrm{~m} h_{w}$ were calculated when the original weight $\gamma_{s w}$ was $1,1.5$ and 2 times. Fig. 9 shows the variation of safety factor with landfill weight $\gamma_{s w}$. It can be seen that:

(1) The safety factor decreases linearly with the increase of severe $\gamma_{s w}$, and this trend increases with the increase of severe $\gamma_{s w}$.

(2) The safety factor decreases with the increase of leachate water level, which indicates that the increase of leachate water level $h_{w}$ aggravates the influence of severe $\gamma_{s w}$ on the safety factor.

\section{Mechanics Parameters of Lining Interface in Landfill}

In order to study the influence of mechanical parameters of the interface between landfill and backing on the stability of landfill under multi-point seismic loads, the cohesive forces $c_{p}$ and $c_{a}$ of the interface 


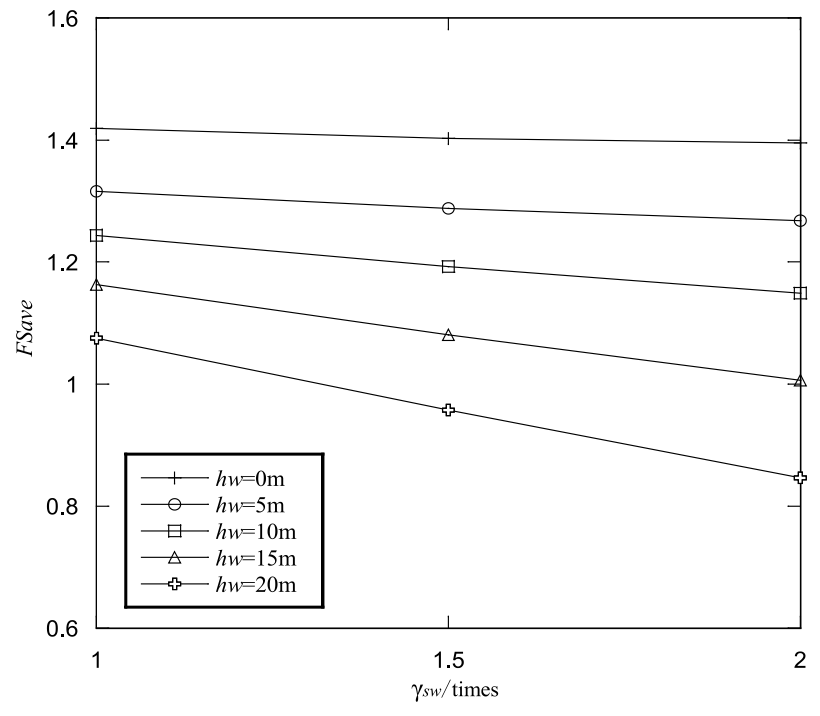

Fig. 9. Relationship between safety factor $F S$ and $\gamma_{s w}$ considering leachates.

between landfill and bottom and backing are calculated at $0,1,2,3,4$ and $5 \mathrm{kPa}$, respectively. The safety factors of friction angle $\delta_{p}$ and $\delta$ are $10^{\circ}, 15^{\circ}, 20^{\circ}, 25^{\circ}$ and $30^{\circ}$, respectively, at $h_{w}$ of $0,5,10,15$ and $20 \mathrm{~m}$. Figs 10 and 11 show the variation of the safety factor with the cohesion $c_{p}$ and friction angle $\delta_{p}$ of the bottom liner surface, and Figs. 12 and 13 show the variation of the safety factor with the cohesion $c_{a}$ and friction angle $\delta_{a}$ of the back liner surface. It can be seen that:

(1) The safety factor increases with the increase of cohesive force $c_{p}, c_{a}$, friction angle $\delta_{p}$ and $\delta_{a}$ at the interface between landfill and bottom and back liner.

(2) Compared with Figs 10 and 11, the influence of friction angle $\delta_{p}$ on the contact surface of landfill bottom

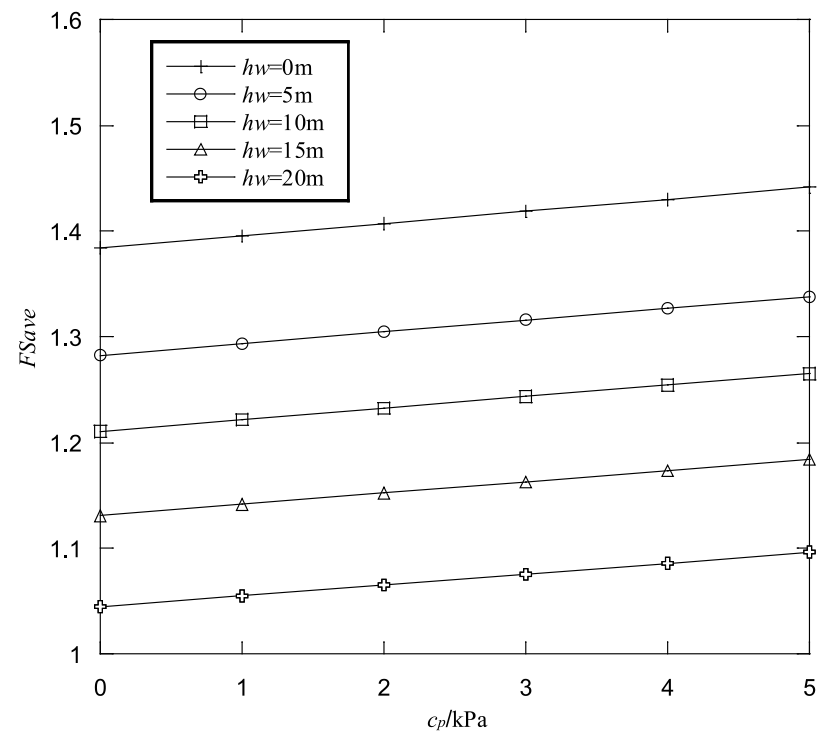

Fig. 10. Relationship between safety factor $F S$ and $c_{p}$ considering leachates.

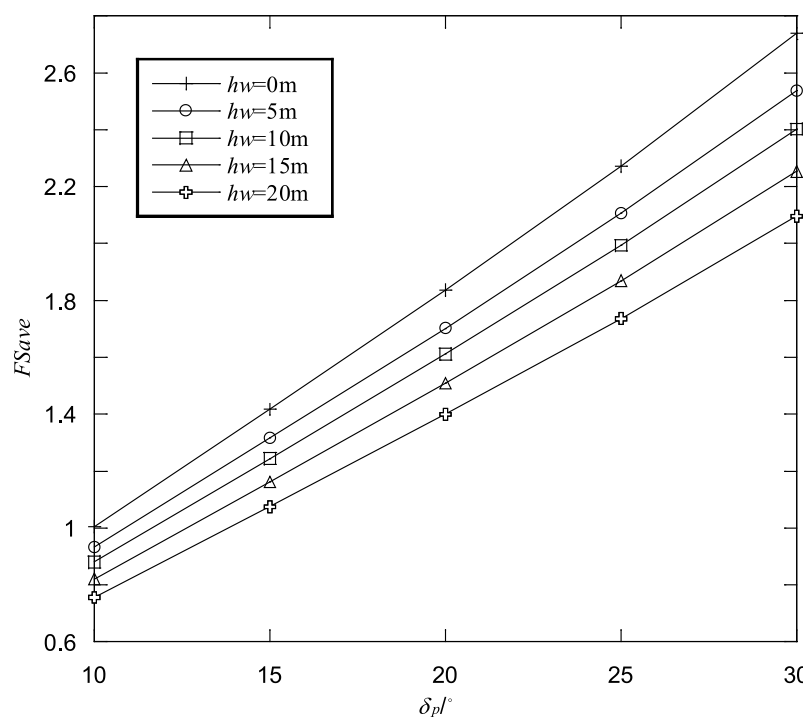

Fig. 11. Relationship between safety factor $F S$ and $\delta_{p}$ considering leachates.

liner is obviously greater than that of cohesion $c_{p}$ on stability. This indicates that when choosing the backing liner of a landfill, the backing with larger friction angle of contact surface should be selected first according to the test data.

(3) Figs 12 and 13 show that the mechanical parameters of the interface between landfill and backing have little effect on slip stability. The reason is that the relative volume of the active block is small and the proportion of the active block in the anti-slip force is small, so the mechanical parameters of backing contact with the landfill have little effect on the overall translational stability.

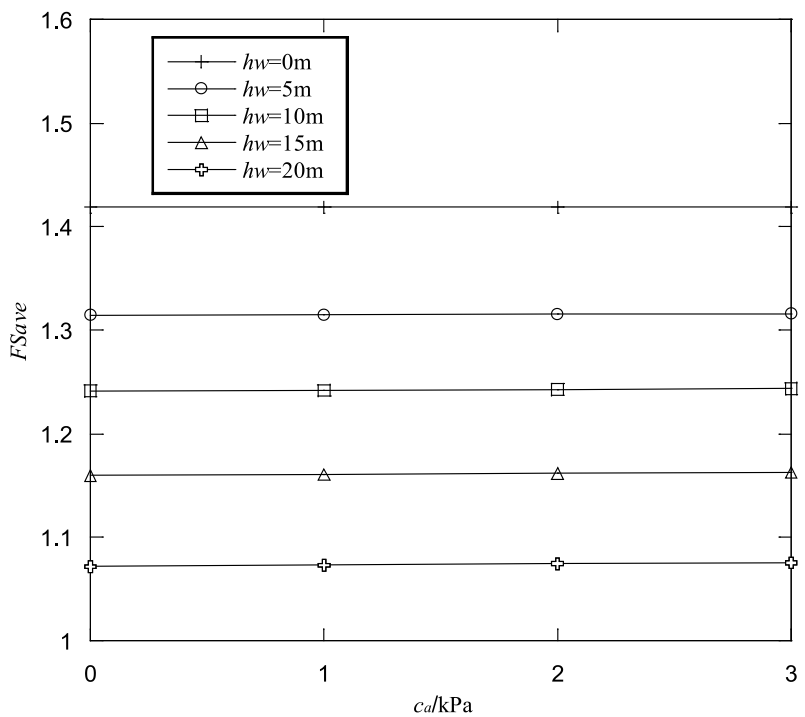

Fig. 12. Relationship between safety factor $F S$ and $c_{a}$ considering leachates. 


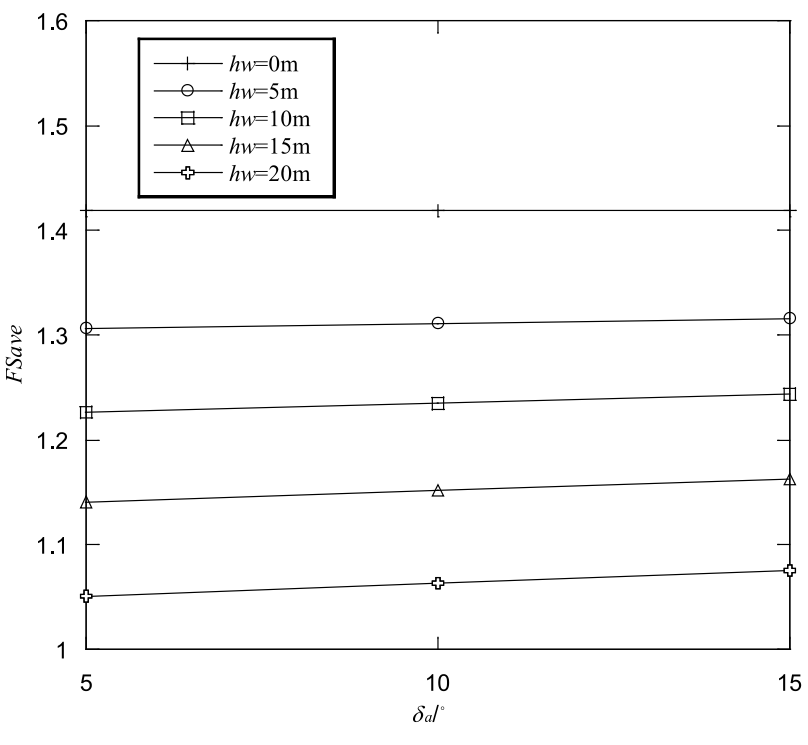

Fig. 13. Relationship between safety factor $F S$ and $\delta_{a}$ considering leachates.

\section{Landfill height}

In order to study the influence of the height of landfill on the overall translational stability under multipoint seismic loads, the safety factor of the landfill with heights $H$ of $40 \mathrm{~m}, 60 \mathrm{~m}$ and $80 \mathrm{~m}$ and $h_{w}$ of $0,5,10,15$ and $20 \mathrm{~m}$ were calculated. Fig. 14 shows the variation of the safety factor of the slip surface with the height of the landfill.

(1) With the increase of height $\mathrm{H}$ of landfill, the safety factor of landfill tends to decrease in a straight line.

(2) With the increase of leachate water level $h_{w}$, the safety factor decreases approximately equally.

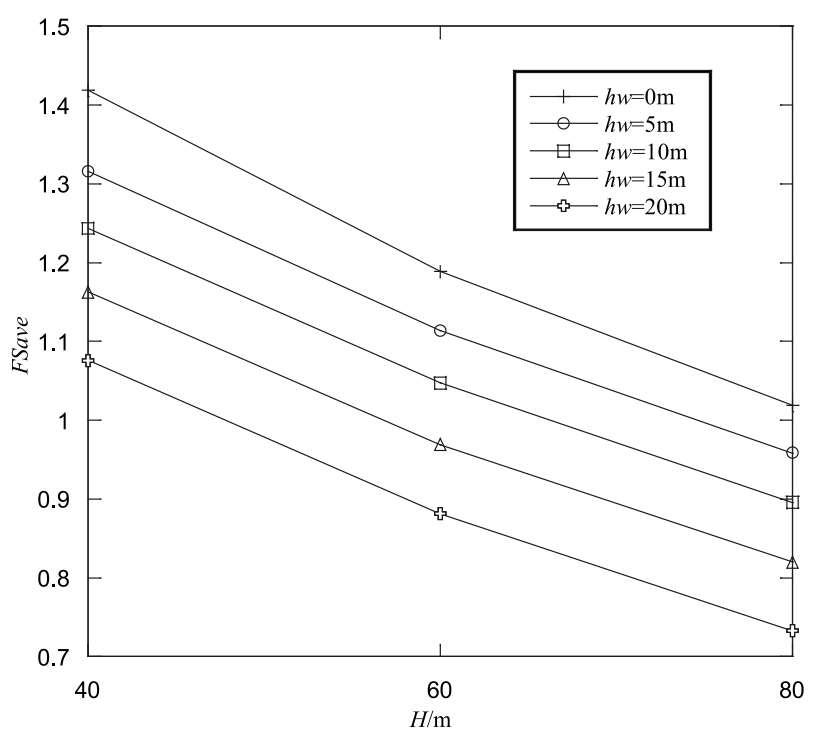

Fig. 14. Relationship between safety factor $F S$ and $H$ considering leachates.
Taking $H=60 \mathrm{~m}$ as an example, when $h_{w}=0,5,10,15$, $20 \mathrm{~m}$, the safety factors are 1.1888, 1.1138, 1.047, 0.9689 and 0.8818 , and the differences are $0.075,0.0668,0.0781$ and 0.0871 .

(3) Due to the limitation of site selection conditions of landfills, most landfills are in the state of overdue service, and their vertical expansion becomes the most direct way to obtain landfill space. However, with the increase of landfill height, its safety factor decreases, and this trend is aggravated in wet and rainy areas due to the high level of leachate. Therefore, the landfill in this type of area should be dilated carefully and the leachate level should be strictly controlled.

\section{Conclusion}

The instability of landfill is directly related to the level of leachate head. In this paper, the calculation method of multi-point seismic load of landfill was deduced. By calculating the pressure of leachate head, a multi-point seismic stability analysis method of landfill considering the influence of leachate is established. By means of this method and a large number of numerical calculations, the effects of waste shear strength, weight, mechanical parameters of the contact surface of liner and geometric parameters of landfill on the stability of landfill under multi-point seismic excitation were analyzed, and the following main conclusions are drawn:

(1) The safety factors of the landfill under multipoint ground motion are always greater than those under single-point ground motion in the previous algorithm. Therefore, taking the influence of multi-point ground motions into consideration during the process of safety assessment is beneficial to the expansion of existing landfills and the extension of service period.

(2) The safety factor considering leachate is smaller than that without consideration; the safety factor decreases approximately with the increase of equidistant distance between $h_{w}$ and the influence of cohesion or internal friction angle on the safety factor. For landfills under actual operation, paying close attention to the leachate level is an important means to ensure safety.

(3) The safety factor decreases linearly with the increase of $\gamma_{s w}$, and this trend increases with the increase of $\gamma_{s w^{*}}$. More attention should be paid to the leachate levels of landfills with greater weight.

(4) The safety factor increases with the increase of cohesive force $c_{p}, c_{a}$, friction angle $\delta_{p}$ and $\delta_{a}$ at the interface between landfill and bottom and back cushions. The influence of friction angle $\delta_{p}$ on the contact surface of landfill bottom liner is greater than that of cohesive force $c$ on stability. When choosing the liner of a landfill, the liner with larger friction angle of contact surface $\delta_{p}$ should be selected first according to the test data.

(5) With the increase of landfill height $H$ and leachate water level $h_{w}$, the safety factor of landfill leachate decreases linearly. This trend is aggravated by the high 
level of leachate in wet and rainy areas. Therefore, the landfill in this type of area should be dilated carefully and the leachate level should be strictly controlled.

\section{Acknowledgements}

This work was supported by the Shandong Provincial Natural Science Foundation of China (ZR2017BEE021).

\section{Conflict of Interest}

The authors declare no conflict of interest.

\section{References}

1. GAO W., BIAN X.C., XU W.J., CHEN Y.M. Storage capacity and slope stability analysis of municipal solid waste landfills. Journal of Performance of Constructed Facilities, 32, 36, 2018.

2. QIAN X.D., KOERNER R.M. Critical interfaces and waste placement in landfill design. Environmental Geotechnics, 4, 160, 2017.

3. KERAMATI M., SHARIATMADARI N., KARIMPOUR-FARD M., SHAHRBABAK M.R.N. Dynamic behavior of MSW materials under cyclic triaxial testing: a case of kahrizak landfill Tehran, Iran. Iranian Journal of Science and Technology-Transactions of Civil Engineering, 40, 75, 2016.

4. KERAMATI M., SHARIATMADARI N., SABBAGHI M., ABEDIN M.S. Effect of confining stress and loading frequency on dynamic behavior of municipal solid waste in kahrizak landfill. International Journal of Environmental Science and Technology, 15, 1257, 2018.

5. ANNAPAREDDY V.S.R., PAIN A., SARKAR S. Seismic translational failure analysis of MSW landfills using modified pseudo-dynamic approach. International Journal of Geomechanics, 17, 86, 2017.

6. FENG S.J., CHANG J.Y., CHEN H.X., ZHANG D.M. Numerical analysis of earthquake-induced deformation of liner system of typical canyon landfill. Soil Dynamics and Earthquake Engineering, 116, 96, 2019.
7. FENG S.J., WU H., LI X. Three-dimensional instability analysis of solid waste landfills under earthquake loading. China Earthquake Engineering Journal, 37, 285, 2015.

8. RUAN X.B., LIN H. Relationship Between Shear Wave Wavelength and Pseudo-Dynamic Seismic Safety Factor in Expanded Landfill. Arabian Journal for Science and Engineering, 40, 2271, 2015.

9. ZHU B., CHEN Y.M., KE H. Seismic stability analysis of extended municipal solid waste landfills. Rock and Soil Mechanics, 29, 1483, 2008.

10. MIAO Y., YAO E.L., RUAN B., ZHUANG H.Y. Seismic response of shield tunnel subjected to spatially varying earthquake ground motions. Tunnelling and Underground Space Technology, 77, 216, 2018.

11. LAIB A., LAOUAMI N., SLIMANI A. Modeling of soil heterogeneity and its effects on seismic response of multi-support structures. Earthquake Engineering and Engineering Vibration, 14, 423, 2015.

12. PENG R., HOU Y.J., ZHAN L.T., YAO Y.P. Back-analyses of landfill instability induced by high water level: case study of Shenzhen landfill. International Journal of Environmental Research and Public Health, 13, 126, 2016.

13. KHOSHAND A., FATHI A., ZOGHI M., KAMALAN H. Seismic stability analyses of reinforced tapered landfill cover systems considering seepage forces. Waste Management \& Research, 36, 361, 2018.

14. QIAN X. Limit equilibrium analysis of translational failure of landfills under different leachate buildup conditions. Water Science and Engineering, 1, 44, 2008.

15. FENG S.J., CHEN Z.W., CHEN H.X., ZHENG Q.T., LIU R. Slope stability of landfills considering leachate recirculation using vertical wells. Engineering Geology, 241, 76, 2018

16. QU T.J., WANG Q.X. Simulation of spatial correlative time histories of multi-point ground motion, part I: fundamental formulas. Earthquake Engineering and Engineering Vibration, 18, 8, 1998.

17. QU T.J., WANG Q.X. Simulation of spatial correlative time histories of multi-point ground motion, part II: application of fundamental formulas. Earthquake Engineering and Engineering Vibration, 18, 25, 1998.

18. DENG X., ZOU D., KONG X. Numerical simulation for shaking-table test of municipal waste landfills. Rock and Soil Mechanics, 33, 623, 2012.

19. QIAN X., KOERNER R.M., GRAY D.H. Translational failure analysis of landfills. Journal of Geotechnical and Geoenvironmental engineering, 129, 506, 2003. 